\title{
Prebent Titanium Elastic Nailing, llizarov Fixation and Bone Grafting for Treating Congenital Pseudarthrosis of the Tibia: Preliminary Outcomes of 15 Cases
}

\section{Xiaoyu Wang}

Shanghai Jiao Tong University Affiliated Sixth People's Hospital

\section{Li Shi}

Shanghai Jiao Tong University Affiliated Sixth People's Hospital

\section{Rui Zhang}

Shanghai Jiao Tong University Affiliated Sixth People's Hospital

\section{Wenbo Wang}

Shanghai Jiao Tong University Affiliated Sixth People's Hospital

\section{Feng Wang}

Shanghai Jiao Tong University Affiliated Sixth People's Hospital

\section{Mengwei Wang}

Shanghai Jiao Tong University Affiliated Sixth People's Hospital

\section{ZeXu}

Shanghai Jiao Tong University Affiliated Sixth People's Hospital

\section{Rongtai Zuo}

Shanghai Jiao Tong University Affiliated Sixth People's Hospital

Jia Xu

Shanghai Jiao Tong University Affiliated Sixth People's Hospital

Qinglin Kang ( $\nabla$ orthokang@163.com )

Shanghai Jiao Tong University Affiliated Sixth People's Hospital https://orcid.org/0000-0001-98250451

\section{Research article}

Keywords: Congenital pseudarthrosis of the tibia (CPT), Intramedullary rod (IM rod), Titanium elastic nail (TEN), llizarow technique

Posted Date: December 28th, 2020

DOI: https://doi.org/10.21203/rs.3.rs-135709/v1 
License: (c) (i) This work is licensed under a Creative Commons Attribution 4.0 International License. Read Full License 


\section{Abstract}

Background: To report the preliminary outcome of treating congenital pseudarthrosis of the tibia (CPT) by using titanium elastic nails (TENs) combined with other surgical procedures including pseudarthrosis resection, autogenous iliac bone grafting and Ilizarov technique, with a mean follow-up time of 4.5 (3.3 to 6.3) years.

Methods: 15 patients with CPT treated by combined surgery including pseudarthrosis resection, titanium elastic nails (TENs) technique, autogenous iliac bone grafting and llizarov fixation between 2013 and 2017 were retrospectively investigated. Signs of bone union, limb length discrepancy (LLD), rate of refracture and degree of residual deformities were reviewed. The AOFAS Ankle Hindfoot scale and measurement of ankle movement were used to evaluate ankle function.

Results: The mean age at index surgery was 110 (24 to 285) months. 13 (86.7\%) patients obtained union of the pseudarthrosis on the first attempt (primary union). The average time to primary union was 4.8 (3 to 7) months. The rest 2 cases achieved union after additional surgeries (secondary union). In terms of complications, refracture occurred in 2 patients (13.3\%) and $5(33.3 \%)$ patients developed pin infection. The mean limb length discrepancy at the final follow up was $14.6(4-41) \mathrm{mm}$. 3 patients $(20 \%)$ had ankle valgus deformities with a mean LDTA of $74.3^{\circ}$ (range, 68 to $81^{\circ}$ ). The average AOFAS score improved from 40.3 (27 to 51) pre-operatively to 76.1 (63 to 87 ) post-operatively. For the patients who received proximal tibial lengthening, the average healing index $(\mathrm{HI})$ was $65.1(57.3$ to 77.8$)$ days $/ \mathrm{cm}$.

Conclusions: Titanium elastic nails (TENs) technique is an ideal intramedullary fixation method in the surgical treatment of CPT. The combination of TENs technique with bone grafting and llizarov fixation has the advantages of early bone union, less injury on metaphyseal and early functional recovery.

\section{Background}

Congenital pseudarthrosis of the tibia (CPT) is a rare orthopedic disease with over half of the patients associated with Neurofibromatosis Type 1 (NF-I) (1). Clinically, anterolateral bowing of the affected limb present at birth, limb length discrepancy (LLD) and pathological fractures with a substantial risk of nonunion are major characterizations of CPT. The affected tibia usually displays impaired bone healing due to segmental dysplasia $(2,3)$. The successful treatment of CPT demands solving more than one issue in the affected limb. The achievement of a healed, functional extremity with minimal diaphyseal deformity or activity restrictions is essential for patients with CPT (4). Numerous surgical procedures including intramedullary (IM) rodding, llizarov fixation, vascularized or non-vascularized bone grafting and application of recombinant human bone morphologic protein, in various combinations, have been developed and achieved variable degrees of improvement $(2,5-7)$. However, common complications such as malunion, implant failure, refracture, limb-length discrepancy, and residual angular deformity remain to compromise the therapeutic outcomes of CPT $(2,8)$. 
Currently, the combined treatment including resection of the pseudarthrosis and surrounding hamartomatous tissue, autogenous bone grafting and internal and external fixation is the most commonly used techniques $(7,9-11)$. Rigid fixation is a crucial factor in the treatment of CPT. The use of intramedullary (IM) rodding technique in treating CPT was first described by Charnley et al. in 1956 and was later modified by Williams et al., which helped to decrease the risk of refracture and revolutionized the operative management of these severe deformities $(12,13)$. The retrograde implanted transplantar intramedullary nail provides improved biomechanical stability for bone consolidation, restores the mechanical axis of the limb and reduces the risk of iterative fracture, while at the expense of length discrepancy, joint stiffness and even damage to the articular surface. In addition, children usually have to receive reoperations as the tibiae outgrow their rods, which leads to interruption of childhood and prolonged disability $(7,14,15)$. Telescopic rods can extend during the growth and consequently decrease the number of reoperations. It should be noted, however, that the application of these rods in children is limited by the small shaft diameter of medullary cavity. Moreover, injury to epiphysis may occur as the end of the telescopic rod still requires to be fixed through epiphysis (16).

The disadvantages of the commonly used IM rods mentioned above encouraged us to make changes to our treatment procedure. Elastic stable intramedullary nails (ESINs, or Nancy nails) were initially developed in 1980s by a group of pediatric surgeons in France (17). The successful outcome of combining ESINs with external fixation for pediatric bone lengthening has led us to improve the existed procedure in treating CPT (18). During the past ten years, the TENs technique, in combination with pseudarthrosis resection, bone grafting and llizarov's fixation, has been applied to treat patients with CPT patients in our institute. This study presents the preliminary outcomes of this new treating protocol and validates its efficacy with regard to surgical procedure, subsequent complications and the comparison with the results of previously used techniques.

\section{Methods}

We retrospectively evaluated the patients with pseudarthrosis of the tibia treated by the same group of senior surgeons at our institute from 2013 to 2017. Combined surgical treatment including pseudarthrosis resection, TENs technique, autogenous iliac bone grafting and llizarov fixation was set as inclusion criteria. Exclusion criteria included pseudarthrosis of the tibia caused by trauma or infection. A total of 15 patients ( 9 boys and 6 girls) with CPT were included. Background characteristics is shown in Table 1. All the cases were unilateral, with 6 cases on the right side and 9 cases on the left side. The pseudarthrosis were all located on the distal third of the leg. 13 patients had a fibular lesion at the time of the index surgery. According to the Crawford classification, 1, 1, 7 and 6 patients were defined as type I, II, III and IV, respectively (19). Mean age at index surgery was 110 months (range, 24 to 285) months and 5 patients had undergone surgery previously in other hospitals. Preoperative measurements were performed, which included examination of skin condition, fibular status and limb length discrepancy. The American Orthopaedic Foot \& Ankle Society [AOFAS] ankle-hindfoot scale was also noted for clinical assessment of ankle function before the index surgery (20). No patient was lost to follow-up. Approval 
was obtained by the research ethics committee at Shanghai Jiao Tong University Affiliated Sixth People's Hospital. All the patients were informed consent to participate and approved the publication of their data.

\section{Surgical Procedure}

All surgeries were performed by the same group of senior surgeons (QL.K.). Iliac crest bone graft was harvested at the beginning of the surgery. Briefly, an incision was made at the anterior superior iliac spine. The outer table of the anterolateral surface of the ilium was exposed subperiosteally and as much cancellous bone as possible was harvested from the supra-acetabular region for subsequent bone grafting. An anterior longitudinal incision was made to expose the affected area of the tibia. The abnormal periosteum and sclerotic bone edges at the pseudarthrosis site were excised. The fibrous tissue, if present at the fibular site in patients with concomitant fibular lesion, was excised.

An intramedullary k-wire was used to fix the osteotomized fibula if the tibial fragments were held apart by an intact fibula. 
Table 1

Demographic details of the patients

\begin{tabular}{|c|c|c|c|c|c|c|c|}
\hline No & Gender & $\begin{array}{l}\text { Previous } \\
\text { surgery }\end{array}$ & $\begin{array}{l}\text { Crawford } \\
\text { type }\end{array}$ & $\begin{array}{l}\text { Fibular } \\
\text { lesion }\end{array}$ & $\begin{array}{l}\text { Age at } \\
\text { index } \\
\text { surgery } \\
\text { (month) }\end{array}$ & Fibular surgery & $\begin{array}{l}\text { Follow } \\
\text { up } \\
\text { period } \\
\text { (years) }\end{array}$ \\
\hline 1 & $\mathrm{~F}$ & Y & III & $Y$ & 35 & $\begin{array}{l}\text { Pseudarthrosis } \\
\text { excision }\end{array}$ & 4.0 \\
\hline 2 & $M$ & $\mathrm{~N}$ & IV & $Y$ & 63 & $\begin{array}{l}\text { Pseudarthrosis } \\
\text { excision; bone graft }\end{array}$ & 4.4 \\
\hline 3 & M & $\mathrm{N}$ & 1 & Y & 83 & $\begin{array}{l}\text { Fibular osteotomy; } \\
\text { intra-medullary rod }\end{array}$ & 3.3 \\
\hline 4 & $\mathrm{~F}$ & $\mathrm{~N}$ & $\|$ & $\mathrm{N}$ & 275 & $\mathrm{~N}$ & 4.1 \\
\hline 5 & $\mathrm{~F}$ & $\mathrm{~N}$ & III & $Y$ & 131 & $\begin{array}{l}\text { Pseudarthrosis } \\
\text { excision; bone graft }\end{array}$ & 4.1 \\
\hline 6 & $\mathrm{~F}$ & $\mathrm{~N}$ & IV & $Y$ & 285 & $\begin{array}{l}\text { Pseudarthrosis } \\
\text { excision; intra- } \\
\text { medullary rod; bone } \\
\text { graft }\end{array}$ & 5.2 \\
\hline 7 & M & $\mathrm{N}$ & III & Y & 45 & $\begin{array}{l}\text { Pseudarthrosis } \\
\text { excision; intra- } \\
\text { medullary rod; bone } \\
\text { graft }\end{array}$ & 3.9 \\
\hline 8 & $\mathrm{~F}$ & $\mathrm{Y}$ & III & $Y$ & 154 & $\begin{array}{l}\text { Pseudarthrosis } \\
\text { excision; intra- } \\
\text { medullary rod }\end{array}$ & 5.8 \\
\hline 9 & $\mathrm{~F}$ & $\mathrm{~N}$ & IV & $\mathrm{N}$ & 55 & $\mathrm{~N}$ & 4.4 \\
\hline 10 & M & $\mathrm{N}$ & III & $Y$ & 43 & $\begin{array}{l}\text { Pseudarthrosis } \\
\text { excision; intra- } \\
\text { medullary rod; bone } \\
\text { graft }\end{array}$ & 6.2 \\
\hline 11 & $M$ & $\mathrm{Y}$ & IV & $Y$ & 48 & $\begin{array}{l}\text { Pseudarthrosis } \\
\text { excision; intra- } \\
\text { medullary rod; bone } \\
\text { graft }\end{array}$ & 4.1 \\
\hline 12 & $M$ & $\mathrm{~N}$ & III & $Y$ & 77 & $\begin{array}{l}\text { Fibular osteotomy; } \\
\text { intra-medullary rod }\end{array}$ & 3.4 \\
\hline 13 & $M$ & $\mathrm{Y}$ & IV & $Y$ & 204 & $\begin{array}{l}\text { Pseudarthrosis } \\
\text { excision; intra- } \\
\text { medullary rod; bone } \\
\text { graft }\end{array}$ & 4.2 \\
\hline 14 & $M$ & $\mathrm{Y}$ & IV & $Y$ & 133 & $\begin{array}{l}\text { Pseudarthrosis } \\
\text { excision; fibular } \\
\text { osteotomy }\end{array}$ & 6.3 \\
\hline
\end{tabular}




\begin{tabular}{|clllllll|}
\hline No & Gender & $\begin{array}{l}\text { Previous } \\
\text { surgery }\end{array}$ & $\begin{array}{l}\text { Crawford } \\
\text { type }\end{array}$ & $\begin{array}{l}\text { Fibular } \\
\text { lesion }\end{array}$ & $\begin{array}{l}\text { Age at } \\
\text { index } \\
\text { surgery } \\
\text { (month) }\end{array}$ & Fibular surgery & $\begin{array}{c}\text { Follow } \\
\text { up } \\
\text { period } \\
\text { (years) }\end{array}$ \\
\hline 15 & $\mathrm{M}$ & $\mathrm{N}$ & $\mathrm{III}$ & $\mathrm{Y}$ & 24 & $\begin{array}{l}\text { Pseudarthrosis } \\
\text { excision; intra- } \\
\text { medullary rod; bone } \\
\text { graft }\end{array}$ & 3.7 \\
\hline
\end{tabular}

Two TENs, with an identical diameter at $30-40 \%$ of the isthmus of the medullary canal, were selected for internal fixation. Before nail insertion, the nails were pre-bent over the length of the bone three times the diameter of the medullary canal. Both nails should be pre-contoured in the same way. The entry points were situated anteriorly on the proximal medial and proximal lateral metaphyseal cortices, $2 \mathrm{~cm}$ distal to the proximal physis. The first nail was inserted into the medullary canal with the nail tip at right angles to the bone shaft, and the nail tip was rotated through $180^{\circ}$ with the inserter to align the nail tip with the axis of the medullary canal. Then the nail was advanced up across the resection site towards the level of $1 \mathrm{~cm}$ distal to the metaphysis of the tibia. The vertex of the arch should be located at the level of the resection site. The second nail was inserted at the insertion point on the opposite side in the same way. The two nails were situated in a shape like the Eiffel Tower (Fig. 1, 2b, 3b). Due to the triangular shape of the tibial medullary canal, both nails tend to lie dorsally, which would result in recurvation. Therefore, before hammering the nails in their final position in the distal metaphysis, the tips of both nails were turned slightly posteriorly in order to achieve the physiological antecurvation of the tibia. Finally, end caps were applied to the nails to reduce the risk of nail migration and soft-tissue irritation, and to facilitate subsequent implant removal. The positions of the nail tips were checked under the image intensifier.

The llizarov ring fixation was then applied to perform realignment and compression osteosynthesis at the pseudarthrosis site, with one ring fixed below the site of pseudarthrosis and one ring fixed above. If limb length discrepancy (LLD) was over $3 \mathrm{~cm}$ and the age of the patient was more than 3 years, proximal tibial lengthening using the llizarov technique was performed concomitantly, with another ring added proximal to the corticotomy site, as described by Cho et al., Choi et al. and Zhu et al. in their published studies (9, $21,22)$. Bone segments proximal and distal to the corticotomy site were fixed with 3 wires. The wires should not be in contact with the TENs. A walking ring was added to eliminate the weightbearing on the foot. Intramedullary nailing with TENs technique was combined in cases of concomitant tibia lengthening for stabilizing the pseudarthrosis site. The harvested cancellous graft was placed around the site of pseudarthrosis of the tibia after the application of the llizarov fixator. The grafted cortex was wrapped at the level of the pseudarthrosis area, secured with the bony barrel constructed by absorbable sutures.

Bone transport, if needed, was started 7 days after the surgery at the rate of $0.5 \mathrm{~mm} /$ day in 4 increments. Active and passive motion of the knee and ankle were advised to prevent joint contracture after the surgery. Union was considered to be achieved with the formation of at least 3 visible bridging cortices in 2 
planes under anteroposterior and lateral radiographs. The criterion used llizarov frame removal was set as the achievement of bone union both at the distraction gap and the pseudarthrosis site. Long leg cast was then applied for 1-2 months. Hereafter patients were recommended to move under partial weightbearing with the support of a Knee-Ankle-Foot-Orthosis until skeletal maturity. In order to minimize the risk of refracture and abnormal tibia bowing, the TENs were left in situ till skeletal maturity but may be changed for longer and thicker ones when the tip of the nails receded into the distal third of the tibia with growth. Other additional surgeries for addressing residual problems include treatment of refracture, deformity correction with hemiepiphysiodesis or osteotomy, surgery for nonunion, nail change for pin site problem and treatment of joint contracture.

\section{Outcome evaluation}

Post-operative radiographs were obtained every month until fixator removal to monitor consolidation and limb length; thereafter, follow-ups were continued every half year until the patients achieved skeletal maturity. Bone union rate and time till union were calculated. Primary union referred to bone united after the first operation without any need for secondary surgeries. Secondary union was labeled when additional surgery was needed to obtain union. Occurrence of refracture was recorded. For evaluation of limb lengthening, healing index $(\mathrm{HI})$ and limb length discrepancy at the final follow-up were measured. The healing index $(\mathrm{HI})$ defined by Aldegheri et al., is expressed as the number of days the fixator was applied per centimeters of new-formed bone regenerate length (23). Limb length was measured radiographically from proximal physis to distal physis of the tibia. It should be mentioned that LLD measurement was performed after the index surgery as LLD might increase due to impaction of bone ends after excision of pseudoarthrosis. Residual deformities, including tibial malalignment and ankle valgus, were assessed by the anteroposterior and lateral radiographs. Additional surgical interventions during the period of follow-up were noted. The American Orthopaedic Foot \& Ankle Society [AOFAS] Ankle Hindfoot scale was used to evaluate ankle function post-operatively. Additional surgical procedures for addressing the subsequent complications and residual deformities were recorded.

\section{Statistical methods}

All statistics were calculated using IBM SPSS software (version 22). Paired t-test was used for evaluating the difference between pre- and post-operative AOFAS score (at last follow-up). The Mann-Whitney U test was performed for analysis of LLD post-operation and at the final follow up. The level of significance was set at $p<0.05$.

\section{Results}

The patients were investigated at a mean follow-up time of 4.5 years (range, 3.3-6.3y) after the index operation. At the final follow-up, all the patients had their external frame removed and could walk with full weight bearing on the treated limb. The TENs were retained in all 15 patients during the latest follow-up. 
All the patients were satisfied with the functional and cosmetic outcomes (Figs. 2 and 3). A total of 24 reoperations were performed to change the undersized TENs at the last follow-up visit (Table 2).

Union of the pseudarthrosis was achieved in $100 \%$ of the cases, with primary union in 13 cases (86.7\%). 2 cases of delayed union at the pseudarthrosis site (case 6 and case 10) achieved union after supplemental allogenous bone graft and replacement of elastic nails. One case with nonunion regarding the bone transport site (case 8) received bone graft and prolonged duration of llizarov fixation (Table 2). The average time to primary union was 4.8 months (range, 3 to 7 months) and for secondary union it was 10.3 months (range, 7 to 13 months). An average number of 1.3 (range, 1 to 2 ) surgeries were performed to achieve union (Table 3).

The average limb length discrepancy after index surgery was $50.1 \mathrm{~mm}$ (range, 13 to $90 \mathrm{~mm}$ ). 2 patients (case 7 and case 15) underwent osteosynthesis of the pseudarthrosis alone as the shortening was anticipated to be no more than $3 \mathrm{~cm}$. The other patients underwent tibia lengthening, with an average healing index $(\mathrm{HI})$ of $65.1 \mathrm{~d} / \mathrm{cm}$ (range, 57.3 to $77.8 \mathrm{~d} / \mathrm{cm}$ ) (Table 3). The mean limb-length discrepancy at the final follow-up was $14.6 \mathrm{~mm}$ (range, $4-41 \mathrm{~mm}$ ). Only one patient (case 10) had residual shortening of over $3 \mathrm{~cm}(41 \mathrm{~mm})$. 
Table 2

Complications and additional treatment of the patients

\begin{tabular}{|c|c|c|c|}
\hline No & $\begin{array}{l}\text { Type of } \\
\text { union }\end{array}$ & Complication & Additional treatment \\
\hline \multirow[t]{2}{*}{1} & $\begin{array}{l}\text { Primary } \\
\text { Union }\end{array}$ & $\begin{array}{l}\text { Valgus malalignment of } \\
\text { left ankle }\end{array}$ & Hemiepiphyseodesis of medial distal tibia \\
\hline & & & Nail change $\times 2$ \\
\hline \multirow[t]{5}{*}{2} & $\begin{array}{l}\text { Primary } \\
\text { Union }\end{array}$ & Refracture & $\begin{array}{l}\text { Cast immobolization, then nail reinsertion with bone } \\
\text { graft and external fixation }\end{array}$ \\
\hline & & $\begin{array}{l}\text { Valgus malalignment of } \\
\text { right ankle }\end{array}$ & $\begin{array}{l}\text { Supramalleolar osteotomy, tibiofibular synostosis } \\
\text { and external fixation }\end{array}$ \\
\hline & & $\begin{array}{l}\text { Valgus malalignment of } \\
\text { right ankle }\end{array}$ & $\begin{array}{l}\text { Hemiepiphyseodesis of medial distal tibia; Nail } \\
\text { change }\end{array}$ \\
\hline & & $\begin{array}{l}\text { Dorsiflexion contracture } \\
\text { of ankle }\end{array}$ & Transfer of tibialis posterior tendon \\
\hline & & & Nail change $\times 2$ \\
\hline \multirow[t]{2}{*}{3} & $\begin{array}{l}\text { Primary } \\
\text { Union }\end{array}$ & Pin infection (grade I) & $\begin{array}{l}\text { Dressing changes and oral administration of } \\
\text { antibiotics }\end{array}$ \\
\hline & & & Nail change $\times 2$ \\
\hline \multirow[t]{2}{*}{4} & $\begin{array}{l}\text { Primary } \\
\text { Union }\end{array}$ & $\begin{array}{l}\text { Valgus malalignment of } \\
\text { left calcaneus }\end{array}$ & $\begin{array}{l}\text { Calcaneal osteotomy with K-wire fixation; } \\
\text { Myotenolysis and lengthening of anterior extensor } \\
\text { muscle }\end{array}$ \\
\hline & & & Nail change \\
\hline \multirow[t]{2}{*}{5} & $\begin{array}{l}\text { Primary } \\
\text { Union }\end{array}$ & Equinus & $\begin{array}{l}\text { Lengthening of the Achilles tendon and tibialis } \\
\text { posterior; Nail change }\end{array}$ \\
\hline & & & Nail change \\
\hline \multirow[t]{4}{*}{6} & $\begin{array}{l}\text { Secondary } \\
\text { Union }\end{array}$ & Delayed consolidation & $\begin{array}{l}\text { Repeat bone grafting and prolonged duration of } \\
\text { Ilizarov fixation }\end{array}$ \\
\hline & & $\begin{array}{l}\text { Valgus deformity of left } \\
\text { knee }\end{array}$ & Medial distal close-wedge osteotomy; Nail change \\
\hline & & $\begin{array}{l}\text { Mild contracture of the } \\
\text { Achilles tendon }\end{array}$ & Tendon lengthening of the Achilles \\
\hline & & $\begin{array}{l}\text { Varus deformity of left } \\
\text { ankle }\end{array}$ & Calcaneal osteotomy; Nail change \\
\hline \multirow[t]{2}{*}{7} & $\begin{array}{l}\text { Primary } \\
\text { Union }\end{array}$ & Pin infection (grade I) & Oral administration of antibiotics \\
\hline & & & Nail change $\times 3$ \\
\hline
\end{tabular}




\begin{tabular}{|c|c|c|c|}
\hline No & $\begin{array}{l}\text { Type of } \\
\text { union }\end{array}$ & Complication & Additional treatment \\
\hline \multirow[t]{3}{*}{8} & $\begin{array}{l}\text { Primary } \\
\text { Union }\end{array}$ & Equinus & $\begin{array}{l}\text { Tendon lengthening of the tibialis posterior and the } \\
\text { Achilles }\end{array}$ \\
\hline & & $\begin{array}{l}\text { Delayed union at the } \\
\text { distraction site of the } \\
\text { tibia }\end{array}$ & Bone grafting; Nail change \\
\hline & & & Nail change \\
\hline \multirow[t]{2}{*}{9} & $\begin{array}{l}\text { Primary } \\
\text { Union }\end{array}$ & $\begin{array}{l}\text { Valgus deformity of } \\
\text { distal tibia }\end{array}$ & Nail change \\
\hline & & & Nail change $\times 2$ \\
\hline \multirow[t]{2}{*}{10} & $\begin{array}{l}\text { Secondary } \\
\text { Union }\end{array}$ & $\begin{array}{l}\text { Delayed consolidation, } \\
\text { Pin infection (grade II) }\end{array}$ & Repeat bone grafting and replacement of the nail \\
\hline & & & Nail change $\times 3$ \\
\hline \multirow[t]{2}{*}{11} & $\begin{array}{l}\text { Primary } \\
\text { Union }\end{array}$ & $\begin{array}{l}\text { Valgus malalignment of } \\
\text { right ankle }\end{array}$ & $\begin{array}{l}\text { Hemiepiphysiodesis of medial distal tibia; Nail } \\
\text { change }\end{array}$ \\
\hline & & & Nail change \\
\hline \multirow[t]{2}{*}{12} & $\begin{array}{l}\text { Primary } \\
\text { Union }\end{array}$ & $\begin{array}{l}\text { Valgus deformity of left } \\
\text { knee }\end{array}$ & Hemiepiphysiodesis of medial proximal tibia \\
\hline & & & Nail change \\
\hline \multirow[t]{2}{*}{13} & $\begin{array}{l}\text { Primary } \\
\text { Union }\end{array}$ & Pin infection (grade II) & Debridement, nail change and drainage of wound \\
\hline & & & Nail change \\
\hline \multirow[t]{3}{*}{14} & $\begin{array}{l}\text { Primary } \\
\text { Union }\end{array}$ & Refracture & Nail reinsertion, bone graft, external fixation \\
\hline & & Pin infection (grade II) & $\begin{array}{l}\text { Debridement, nail change and oral administration of } \\
\text { antibiotics }\end{array}$ \\
\hline & & & Nail change $\times 2$ \\
\hline 15 & $\begin{array}{l}\text { Primary } \\
\text { Union }\end{array}$ & $\mathrm{N}$ & Nail change $\times 2$ \\
\hline
\end{tabular}


Table 3

Bone union, refracture and length discrepancy of the patients

\begin{tabular}{|c|c|c|c|c|c|c|c|}
\hline No & $\begin{array}{l}\text { Union } \\
\text { time } \\
\text { (month) }\end{array}$ & $\begin{array}{l}\text { Number of } \\
\text { operations } \\
\text { before union }\end{array}$ & $\begin{array}{l}\text { Time of } \\
\text { refracture } \\
\text { after surgery }\end{array}$ & $\begin{array}{l}\text { Number of } \\
\text { reoperations }\end{array}$ & $\begin{array}{l}\text { Po- } \\
\text { Op } \\
\text { LLD } \\
(\mathrm{mm})\end{array}$ & $\begin{array}{l}\text { LLD at } \\
\text { final } \\
\text { follow-up } \\
(\mathrm{mm})\end{array}$ & $\begin{array}{l}\text { Healing } \\
\text { index } \\
\text { (days/cm) }\end{array}$ \\
\hline 1 & 6 & 1 & $N$ & 3 & 42 & 6 & 61.4 \\
\hline 2 & 5 & 2 & 3 year & 6 & 31 & 12 & 60.6 \\
\hline 3 & 5 & 1 & $\mathrm{~N}$ & 2 & 50 & 4 & 68.3 \\
\hline 4 & 4 & 1 & $\mathrm{~N}$ & 2 & 90 & 8 & 70.4 \\
\hline 5 & 7 & 1 & $\mathrm{~N}$ & 2 & 50 & 10 & 66.1 \\
\hline 6 & 11 & 2 & $\mathrm{~N}$ & 4 & 87 & 7 & 77.8 \\
\hline 7 & 3 & 1 & $\mathrm{~N}$ & 3 & 27 & 11 & $\mathrm{~N}$ \\
\hline 8 & 7 & 1 & $\mathrm{~N}$ & 3 & 63 & 9 & 71 \\
\hline 9 & 3 & 1 & $\mathrm{~N}$ & 3 & 32 & 14 & 60.1 \\
\hline 10 & 13 & 2 & $\mathrm{~N}$ & 4 & 60 & 41 & 60.4 \\
\hline 11 & 3 & 1 & $\mathrm{~N}$ & 2 & 37 & 22 & 59.2 \\
\hline 12 & 5 & 1 & $\mathrm{~N}$ & 2 & 36 & 17 & 57.3 \\
\hline 13 & 6 & 1 & $\mathrm{~N}$ & 2 & 87 & 23 & 69.7 \\
\hline 14 & 4 & 2 & 10 months & 4 & 46 & 15 & 63.7 \\
\hline 15 & 4 & 1 & $\mathrm{~N}$ & 2 & 13 & 20 & $\mathrm{~N}$ \\
\hline
\end{tabular}

7 patients developed residual deformities, and require further operations (Table 2). Among them, ankle deformity was revealed by anteroposterior weight-bearing radiographs in 4 patients (case 1, 2, 6 and 11). The rate of residual deformity was similar to or better than that reported in earlier series $(15,24,25)$. Three patients (case 1, 2 and 11) developed valgus deformity of the ankle, with lateral distal tibial angle (LDTA) of $74^{\circ}, 68^{\circ}$ and $81^{\circ}$, respectively. Medial distal hemiepiphysiodesis was applied in all 3 patients and 1 patient (case 2) received additional supramalleolar osteotomy, tibiofibular synostosis and external fixation. 2 patients (case 6 and 12) developed knee valgus. One patient (case 6) received a subsequent medial distal close-wedge osteotomy on femur and the other one (case 12) received hemiepiphysiodesis of medial proximal tibia. Two patients (case 5,8) developed equinus and received tendon lengthening of the Achilles. As shown in Table 4, the mean pretreatment AOFAS score for all 15 patients was 40.3 (range, 27 to 51), which increased significantly to 76.1 (range, 63 to 87) at the time of the last follow-up ( $p$ 0.05). Tibiotalar joint was free in 12 patients at the final follow up, with an average range of movement of 
$21.7^{\circ}$ during dorsiflexion and $38.3^{\circ}$ during plantar flexion. Subtalar range of motion was satisfactory in 12 patients, with an average range of movement of $10.3^{\circ}$ during eversion and $18.3^{\circ}$ during inversion.

Other complications include refracture and pin tract infection (Table 2). Refracture occurred in 2 patients (13.3\%, case 2 and 14), both after removal of the external fixators ( 3 years and 10 months after index surgery). 1 patient (case 2 ) refracture had fibular pseudarthrosis. In case 2 , the refracture was treated with casting. Ilizarov fixator to compress at the refracture site and nail reinsertion were also applied in both cases. Pin tract infection was identified in 5 patients, with 2 cases of grade-I and 3 cases of grade-II infection. Those with grade I infection were settled with dressing changes and oral antibiotics, while for persistent or grade II infection, wires had to be changed or withdrawn. In total, 44 additional procedures were performed for the entire cohort of 15 patients (mean, 2.9 procedures per patient). There were no cases of neurovascular complications or amputation in our study. 
Table 4

Pre- and post-operative ankle function of the patients

\begin{tabular}{|c|c|c|c|c|c|}
\hline No & $\begin{array}{l}\text { Residual } \\
\text { angular } \\
\text { deformity }\end{array}$ & $\begin{array}{l}\text { Pre-op } \\
\text { AOFAS } \\
\text { score }\end{array}$ & $\begin{array}{l}\text { AOFAS } \\
\text { score at } \\
\text { last } \\
\text { follow-up }\end{array}$ & $\begin{array}{l}\text { Tibiotalar range of motion } \\
\left(^{\circ}\right) \\
\text { (dorsiflexion/plantarflexion) }\end{array}$ & $\begin{array}{l}\text { Subtalar range of } \\
\text { motion }\left({ }^{\circ}\right) \\
\text { (eversion/inversion) }\end{array}$ \\
\hline 1 & 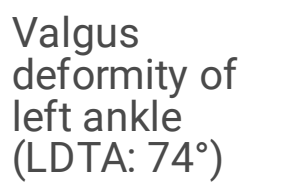 & 39 & 84 & $20 / 40$ & $10 / 15$ \\
\hline 2 & $\begin{array}{l}\text { Valgus } \\
\text { deformity of } \\
\text { right ankle } \\
\left(\text { LDTA: } 68^{\circ}\right)\end{array}$ & 42 & 71 & $25 / 45$ & $10 / 30$ \\
\hline 3 & $N$ & 27 & 79 & $20 / 40$ & $10 / 20$ \\
\hline 4 & $\begin{array}{l}\text { Valgus } \\
\text { deformity of } \\
\text { left calcaneus }\end{array}$ & 37 & 79 & $20 / 40$ & $15 / 15$ \\
\hline 5 & Equinus & 34 & 83 & $25 / 40$ & $15 / 20$ \\
\hline \multirow[t]{2}{*}{6} & $\begin{array}{l}\text { Varus } \\
\text { deformity of } \\
\text { left ankle } \\
\left(\text { LDTA: } 105^{\circ}\right)\end{array}$ & 49 & 63 & $5 / 10$ & $0 / 5$ \\
\hline & $\begin{array}{l}\text { Valgus } \\
\text { deformity of } \\
\text { left knee } \\
\left(\text { mLDFA: } 80^{\circ}\right)\end{array}$ & & & & \\
\hline 7 & $\mathrm{~N}$ & 51 & 80 & $25 / 40$ & $10 / 25$ \\
\hline 8 & Equinus & 33 & 73 & $10 / 20$ & $5 / 5$ \\
\hline 9 & $\mathrm{~N}$ & 47 & 78 & $25 / 35$ & $15 / 15$ \\
\hline 10 & $\mathrm{~N}$ & 49 & 87 & $20 / 40$ & $10 / 20$ \\
\hline 11 & $\begin{array}{l}\text { Valgus } \\
\text { deformity of } \\
\text { right ankle } \\
\left(\text { LDTA: } 81^{\circ}\right)\end{array}$ & 48 & 72 & $25 / 40$ & $15 / 25$ \\
\hline 12 & $\begin{array}{l}\text { Valgus } \\
\text { deformity of } \\
\text { left knee } \\
\left.\text { (MPTA: } 96^{\circ}\right)\end{array}$ & 43 & 63 & $5 / 10$ & $5 / 0$ \\
\hline 13 & $N$ & 39 & 76 & $15 / 30$ & $10 / 10$ \\
\hline 14 & $\mathrm{~N}$ & 38 & 71 & $20 / 30$ & $10 / 20$ \\
\hline
\end{tabular}




\begin{tabular}{|clllll|}
\hline No & $\begin{array}{l}\text { Residual } \\
\text { angular } \\
\text { deformity }\end{array}$ & $\begin{array}{l}\text { Pre-op } \\
\text { AOFAS } \\
\text { score }\end{array}$ & $\begin{array}{l}\text { AOFAS } \\
\text { score at } \\
\text { last } \\
\text { follow-up }\end{array}$ & $\begin{array}{l}\text { Tibiotalar range of motion } \\
\left.\mathbf{(}^{(}\right)\end{array}$ & $\begin{array}{l}\text { Subtalar range of } \\
\text { (dorsiflexion/plantarflexion) }\end{array}$ \\
\hline 15 & $N$ & 28 & 82 & $20 / 40$ & $\begin{array}{l}\left(^{\circ}\right) \\
\text { (eversion/inversion) }\end{array}$ \\
\hline
\end{tabular}

\section{Discussion}

The achievement of skeletal maturity with functional utility and anatomic alignment of the bone is the primary goal of treating CPT $(3,4)$. Among various surgical techniques that have been developed to optimize the outcomes in treating CPT, the llizarov technique has been proved to be valuable in promoting high rate of union through compression, dealing with limb length discrepancy via diaphyseal transfer and addressing angular deformities concomitantly. However, the prevalence of refracture after removal of the fixator is the main concern. Treating with the llizarov frame alone is also challenged by tissue intervention due to pins and $\mathrm{K}$-wires passing through muscle compartments and discomfort led by prolonged frame wearing $(22,26-28)$.

IM fixation was the primary choice in union achievement and protection against refracture, with sufficient biomechanical stability provided $(15,29)$. The combination of the llizarov technique and intramedullary fixation provides adequate fixation after surgery and significantly cuts the days of frame wearing, which help to avoid the drawbacks and discomfort brought about when utilizing the external frame alone (3). In a series of 15 cases who received IM nailing combined with llizarov fixation, Agashe et al. reported that 14 patients (93.3\%) achieved union, with primary union in 6 patients and 8 patients achieved union after secondary procedures. During the 4.2-year follow-up period, only 1 patient (6.7\%) developed refracture (7). Dobbs et al. reported that trans-ankle Williams rod stabilization showed satisfactory long-term outcomes, with initial consolidation occurred in 18 (85.7\%) of 21 patients (15). In a retrospective study performed by Shah et al., all 11 patients showed union after treatment with retrograde intramedullary rodding, with only 5 cases of refracture (14).

For a long period, due to the high rate of refracture, pediatric surgeons were compelled to focus on successful osteosynthesis rather than the sequelae of CPT, such as joint stiffness and arthritic change led by trans-ankle fixation; metaphyseal irritation and growth failure led by metaphyseal intrusion; and even failure of IM fixation due to inadequate space for nail interlocking in pediatric patients $(7,14,16,30$, 31). The disadvantages of the commonly used IM rods mentioned above encouraged us to make changes in our treatment. In our study, two prebent TENs were positioned in an "Eiffel Tower" shape in the medullary canal of the affected tibia, with their respective convexities facing each other. Obviously, this elastic deformation within the medullary canal creates a bending moment within the long bone that is not rigid but stable enough to provide effective support for preventing further refracture and promoting solid union. As shown in Fig. 1a, the "Eiffel Tower" shaped elastic internal frame ensures flexural, translational, rotational and axial stability under external forces. In addition, extensive bone formation that ensures 
stability after removal of the external fixator was also reported to occur along the tract of the intramedullary nails (18).

The combination of IM rodding, circular external fixation and iliac bone grafting have been generally accepted as an effective procedure in protecting against refracture, promoting alignment control with high fusion rate and contributing to early removal of external fixator $(7,9,11,25,32)$. Since 2013 , we applied prebent TENs instead of using conventional IM rod for internal fixation. Our study has shown favorable results, with primary union obtained in $86.7 \%$ patients. An average number of 1.3 (1 to 2 ) surgeries were performed to achieve solid union for each patient, which is in line with that reported previously (11). Refracture occurred in only 2 (13.3\%) of 15 patients. All obtained union of the refracture site after additional surgery. Most other studies show similar or higher refracture rates for various methods (3). 12 refractures (23.2\%) occurred in 21 patients treated by a Williams rod (15). Refracture occurred in $13(23.2 \%)$ of 56 patients treated with combined surgery including pseudarthrosis resection, intramedullary Williams rodding, autogenous iliac bone grafting and Ilizarov's fixator in the Zhu et al. study (9). In a recent study using combined techniques of hamartoma resection, periosteal grafting, circular external fixator application, and intramedullary rodding, 5 (29.4\%) of 17 CPT cases were complicated by refractures (10). As additional refractures may occur before patients reach skeletal, final outcomes should be assessed after all the patients have reached this milestone. Dobbs et al. noted that the frequency of refracture was higher when a fibular pseudarthrosis was not treated (15). Cho et al. reported a higher risk of refracture when the fibula remained ununited (26). Agashe et al. concluded that undue stress led by the persistent malalignment of the tibia and fibula, loss of intramedullary fixation and non-compliance with external bracing regimen are three major causes of refracture (7). Although we followed these suggestions carefully, two cases of refracture still occurred. In one patient (case 2), the occurrence of refracture was probably because of persistent ankle valgus deformity and fibular pseudoarthrosis. In another patient (case 14), the patient did not wear the brace and refracture occurred after major trauma.

Paley defined the success probability as:

\section{Success probability $=$ Union rate $\times[1-$ Mean refracture rate $]$}

He reported that on average, success probability was $40 \%$ in intramedullary rodding, $57 \%$ in the llizarov method and $58 \%$ in intramedullary rodding combined with the llizarov method (2). In our study, the success probability was $69.3 \%$.

To prevent refracture, an intramedullary rod was suggested to be maintained in situ until skeletal maturity $(7,15)$. With longitudinal growth of lower extremity, the distal part of the tibia, the ankle, and the foot migrate distally while the rod remains in place. Thus, reoperations are usually required to push the rod across the ankle joint $(16,33)$. Telescopic rods, such as Bailey-Dubow and Sheffield expandable rods, can elongate as the child grows, which helps to decrease the number of reoperations required for these children. However, knee and ankle arthrotomies are still required for a tibial insertion of 2 telescoping components $(31,34)$. The subsequently developed Fassier-Duval Rod managed to further decrease the 
reoperation rate and complication rate by making the insertion with a single proximal entry $(16,35)$. Unfortunately, due to the lack of longitudinal and rotational stability, the sole use of Fassier-Duval rod fixation in patients with severe underlying bone pathology of CPT end up with discouraging nonunion, collapse ("negative telescoping") and consecutive joint intrusion (16). The high cost also limits its wide acceptance in the developing area, such as mainland China, where public health care is rudimentary. On the contrary, entry points of the TENs were set distal to the proximal physis and were relatively less invasive during further nail changing as the removal and insertion of the nails did not require ankle arthrotomies.

In order to decrease the prevalence of ankle stiffness, Dobbs et al. used the solid two-part Williams intramedullary rod (the rod assembly consists of an indwelling rod and an insertion rod) and recommended surgically advancing the rod out of the ankle joint soon after the pseudarthrosis has healed (15). However, metaphyseal irritation and arthritic change of ankle joint, which results in restricted joint mobility and growth failure, remains as the rod is advanced antegrade across the ankle joint and out through the heel pad during insertion. The ankle joint was usually immobilized by rod transfixation for nearly two years after rod insertion $(14,15,29,36)$. Migration passage of the IM nail through the growth plate may lead to the formation of fibrous bridge (30). Thus, techniques that require the rod positioned across the ankle and subtalar joint are less desirable. Custom interlocking intramedullary nails may decrease the prevalence of ankle stiffness as it does not transfix the ankle joint. However, it is too large for younger patients and it is not suitable for patients in whom the segment distal to the pseudarthrosis is not long enough to accommodate adequate fixation (29). Agashe et al. used the antegrade method of intramedullary nailing which started from the proximal tibia and passed through the "fracture" till the level of the ankle. Ankle motion and achievement of union was satisfied in most of the CPT patients. However, the direction of nailing is relatively dependent on the location of the CPT, since the extremely distal location of the pseudarthrosis, may still require a transplantar nail and end up with poor ankle function (7). In our study, entry points of the elastic nails were set distal to the proximal physis and the ends of the nails were at the level of $1 \mathrm{~cm}$ distal to the metaphysis of tibia, which protects the ankle joints from being jeopardized by classical rodding through the ankle. Range of motion in tibiotalar and subtalar joints was optimal in $12(80 \%)$ patients. Only 3 patients in our study developed subtalar and tibiotalar stiffness, probably due to multiple operations for attainment of union (case 6 and case 8), retrograde intramedullary rodding in the previous failed surgery (case 8 and case 15) and relatively distal location of pseudoarthrosis (case 15).

Similar to previous reports, ankle valgus deformities remained to be the most common residual deformities in our study, which occurred in 3 of 15 patients $(20 \%)$ and all of them had received surgeries on fibular lesions. There seems to be a trend toward an increased rate of ankle valgus deformity postoperatively in the patients who had a fibular pseudarthrosis, which may due to a high position of the fibular distal epiphysis and an asymmetric growth of the distal tibial physis that grows more medially than laterally $(29,32)$. In addition, proximal migration of the distal fibula causes the talus to move follow the fibula, which contributes to ankle valgus and lateral subluxation of the ankle joint. The resultant instability of the ankle increases the risk of refracture $(2,7,15,37)$. Thus, re-establishment of the integrity 
of the fibula is essential for CPT treatment. The distal tibiofibular synostosis is useful in fibular healing, deformity control and refracture treatment, as described by Thabet et al (5). According to our clinical experience, hemi-epiphysiodesis is the easiest method to correct ankle valgus in CPT children with enough growth potential, as hemi-epiphysiodesis is less invasive and can reduce the risk of nonunion brought by corrective osteotomy. In our study, timely and additional procedures such as medial distal hemi-epiphysiodesis, tibiofibular synostosis and supramalleolar osteotomy with external fixation showed good outcomes in addressing ankle valgus deformity over $5^{\circ}$, which is also reported in previous reports $(2,5,8)$. At the last follow-up, all three patients did not report any clinical symptoms such as pain or limping. Agashe et al. reported that under the treatment of llizarov technique combined with intramedullary rodding, the mean AOFAS score increased from 40 to 64 during a mean follow-up time of 4.5 years (7). Our study presents relatively favorable results, with the average AOFAS increased from 40.3 to 76.1. Although a relatively longer follow up period in our study (6.5 years) may lead to a slightly higher AOFAS score at the final follow up, it is still obvious that the ankle function improved greatly during the follow-up period. Only two cases developed equinus deformity. For cases whose intramedullary nailing was in the tibia, passive and active ankle dorsiflexion may help to prevent equinus deformity.

Length discrepancy is a common challenge resulting from inhibited growth of distal physis, surgical resection and bone resorption at pseudarthrosis (2). Pollon et.al reported that motorised intramedullarylengthening nail (Fitbone ${ }^{\circledR}$, Wittenstein, Igersheim, Germany) successfully addressed $5.5 \mathrm{~cm}$ of lower limb shortening in an 18-year-old CPT patient who had already obtained bone union by Masquelet induced-membrane technique and internal fixation (33). However, due to the high cost, it has not yet been established as a routine device. In developing countries where the telescopic rod or intramedullarylengthening nail is not available, typic methods such as lengthening the shorter leg, arresting the growth of the contralateral leg and a combination of the two procedures are the indispensable methods to equalize limb length discrepancy. Choi et al. and Zhu et al. both suggested that LLD of $3 \mathrm{~cm}$ was the threshold for limb lengthening as functional sequelae and limping gait might occur when the residual LLD was $>3 \mathrm{~cm}(9,22)$. Later, Zhu et al. presented the clinical experience that the indication and time window of proximal tibia lengthening in children was more than $4 \mathrm{~cm}$ and two years after the initial union of pseudarthrosis (38). We agree with the treatment threshold of $4 \mathrm{~cm}$ LLD suggested by Zhu et al. However, it should be noted that proximal tibial lengthening in CPT patients is characterized by a high frequency of poor bone regeneration with abnormal callus at the distraction site $(21,38)$. Postponing the limb lengthening will lead to more limb length discrepancy to be corrected, prolonged fixator wearing, increased $\mathrm{HI}$ index and a higher risk of poor bone regeneration. Thus, we performed proximal tibia lengthening in patients with limb length discrepancy of over $3 \mathrm{~cm}$. Otherwise, a shoe-lift was applied according to the patients' willingness.

Choi et al. performed 27 proximal tibial lengthening in 22 patients, some of whom had repeated lengthening. The average healing index was $89 \mathrm{~d} / \mathrm{cm}$ (range, 22-280 d/cm). Proximal tibia dysplasia and repeated lengthening were identified as the risk factors of poor regenerate bone formation. For patients with the signs of proximal tibia dysplasia (trumpet-shaped narrowing, anterior inclination of the proximal physis, and anterior cortex concavity), they recommend the physeal distraction technique. However, they 
also pointed out that the physeal distraction technique has potential risks of secondary joint infection and premature physeal arrest (21). In our study, we performed tibia lengthening and compression of the pseudarthrosis concomitantly with TENs retained in the medullary cavity for avoiding implanting a second fixator and protection of the pseudarthrosis site. Zhu et al. introduced their experience of concomitant proximal tibial lengthening carried out in 56 patients. At the final follow-up (mean 5.2 years, range, 3 to 6.7 years), 16 (28.6\%) patients had an average $2.2 \mathrm{~cm}$ LLD (range, $1.5-4.2 \mathrm{~cm}$ ). In their later study, they performed proximal tibia lengthening 2 years after initial union of pseudarthrosis and suggested that proximal tibial lengthening at this point would have no side effect on the pseudarthrosis. The average $\mathrm{HI}$ was $63.1 \mathrm{~d} / \mathrm{cm}$ (range, $47-77 \mathrm{~d} / \mathrm{cm}$ ). 8 of 11 cases developed proximal tibial dysplasia, with an average $\mathrm{HI}$ of $67 \mathrm{~d} / \mathrm{cm}$. None of the cases had refracture or nonunion of the distraction gap. The average $\mathrm{HI}$ in our study was $65.1 \mathrm{~d} / \mathrm{cm}$ (range, 57.3 to $77.8 \mathrm{~d} / \mathrm{cm}$ ), which is comparable with the results presented in earlier studies. One stage lengthening may affect the healing process at the pseudarthrosis site while postponing tibial lengthening may cause larger LLD and a prolonged period of external fixation (38). Due to the retrospective nature of the study and the heterogeneous degree of limb discrepancy, the value of TENs technique in limb lengthening still cannot be confirmed directly from our study. The question therefore arises as to at what time window the proximal tibia lengthening procedure together with different intramedullary nailing techniques would yield the most favorable outcomes in terms of fewer complications, shorter duration of external fixation, a higher rate of union and lower chance of refracture.

The small number of patients is the limitation of this study. As CPT is a rare disease, more multicenter studies with larger numbers of patients included should be carried out for more meaningful conclusions. Follow-up period is not long enough to document the outcomes of these younger patients until skeletal maturity. The true success of treating CPT in a growing child can be confirmed only by following the children until maturity. In all, a well-designed prospective study is required in the future to fully investigate the advantages and drawbacks of the titanium elastic nailing technique.

In conclusion, this study demonstrated that the application of prebent titanium elastic nails (TENs), combined with bone grafting and application of circular external fixator, is a viable option for CPT in achieving and maintaining union. The advantages of the present surgical procedure lie in providing good stability and protection against refracture. The readily availability is another factor that makes it an alternative first-line surgical option for young children in the developing world. Moreover, compared with other rodding techniques, the TENs technique poses less injury to ankle joint and metaphysis, which effectively avoids ankle stiffness and reduces negative impact on tibia growth. It is necessary to follow up more patients until skeletal maturity and to evaluate its long-term outcome.

\section{Abbreviations}

ROM: Range of motion, LLD: Limb length discrepancy, Congenital pseudarthrosis of the tibia: CPT, intramedullary rod: IM rod, Titanium elastic nail: TEN 


\section{Declarations}

The manuscript has been read and approved by all named authors. We further confirm that the order of authors listed in the manuscript has been approved by all of authors.

\section{Ethics approval and consent to participate}

The Ethics Committee of Shanghai Jiao Tong University Affiliated Sixth People's Hospital approved the current study. All clinical investigations were performed in accordance with the guidelines of the Declaration of Helsinki. Written informed consent to participate in the study was obtained from the patients. For patients under 16 years old, written informed consent was obtained from their guardian.

\section{Consent for publication}

Written consent for publication was obtained from study participants.

\section{Availability of data and materials}

The datasets in the current study are available from the corresponding author on reasonable request.

\section{Competing interests}

The authors declare that they have no relevant conflicts of interest to disclose in the preparation and completion of the manuscript.

\section{Funding}

This work was supported by the National Natural Science Foundation of China (grant nos. NSFC 81572121 and 81802156). The funders provided assistance in patient follow-up and data collection. They also help in manuscript preparation, such as organization of the structure and modification of the text.

\section{Authors' contributions}

All authors contributed to the study conception and design. Material preparation and data collection were performed by XYW and LS. The first draft of the manuscript was written by XYW. XYW and RZ analysed the data. XYW and WBW created the tables. FW, MWW, ZX, RTZ and JX commented on the previous versions of the manuscript. All authors read and approved the final manuscript.

\section{Acknowledgements}

We would like to thank Mr. Dongyuan Xu for his help in creating the figures.

\section{Conflicts of Interest}

The authors declare that they have no conflict of interest. 


\section{References}

1. Hefti F, Bollini G, Dungl P, Fixsen J, Grill F, Ippolito E, et al. Congenital pseudarthrosis of the tibia: history, etiology, classification, and epidemiologic data. J Pediatr Orthop B. 2000;9(1):11-5.

2. Paley D. Congenital pseudarthrosis of the tibia: biological and biomechanical considerations to achieve union and prevent refracture. Journal of children's orthopaedics. 2019;13(2):120-33.

3. Kesireddy N, Kheireldin RK, Lu A, Cooper J, Liu J, Ebraheim NA. Current treatment of congenital pseudarthrosis of the tibia: a systematic review and meta-analysis. Journal of pediatric orthopedics Part B. 2018;27(6):541-50.

4. O'Donnell C, Foster J, Mooney R, Beebe C, Donaldson N, Heare T. Congenital Pseudarthrosis of the Tibia. JBJS Rev. 2017.

5. Thabet AM, Paley D, Kocaoglu M, Eralp L, Herzenberg JE, Ergin ON. Periosteal grafting for congenital pseudarthrosis of the tibia: a preliminary report. Clinical orthopaedics and related research. 2008;466(12):2981-94.

6. Jahmani R, Alorjani M. Anterolateral Bowing of Congenital Pseudoarthrosis of Tibia Treated by Percutaneous Osteotomy and Gradual Correction Using Taylor Spatial Frame, then Late Insertion of a Fussier-Duval Nail: A Case Report. Am J Case Rep. 2018;19:426-30.

7. Agashe MV, Song SH, Refai MA, Park KW, Song HR. Congenital pseudarthrosis of the tibia treated with a combination of llizarov's technique and intramedullary rodding. Acta orthopaedica. 2012;83(5):515-22.

8. Inan M, El Rassi G, Riddle EC, Kumar SJ. Residual deformities following successful initial bone union in congenital pseudoarthrosis of the tibia. J Pediatr Orthop. 2006;26(3):393-9.

9. Zhu GH, Mei HB, He RG, Liu YX, Liu K, Tang J, et al. Combination of intramedullary rod, wrapping bone grafting and llizarov's fixator for the treatment of Crawford type IV congenital pseudarthrosis of the tibia: mid-term follow up of 56 cases. BMC musculoskeletal disorders. 2016;17(1):443.

10. Kocaoğlu M, Eralp L, Bilen FE, Civan M. Congenital pseudarthrosis of the tibia: Results of circular external fixation treatment with intramedullary rodding and periosteal grafting technique. Acta orthopaedica et traumatologica turcica. 2020;54(3):245-54.

11. Shabtai L, Ezra E, Wientroub S, Segev E. Congenital tibial pseudarthrosis, changes in treatment protocol. Journal of pediatric orthopedics Part B. 2015;24(5):444-9.

12. Charnley J. Congenital pseudarthrosis of the tibia treated by intramedullary nail. J Bone Joint Surg Am. 1956;38-a(2):283-90.

13. Williams PF. FRAGMENTATION AND RODDING IN OSTEOGENESIS IMPERFECTA. The Journal of bone and joint surgery British volume. 1965;47:23-31.

14. Shah H, Doddabasappa SN, Joseph B. Congenital pseudarthrosis of the tibia treated with intramedullary rodding and cortical bone grafting: a follow-up study at skeletal maturity. Journal of pediatric orthopedics. 2011;31(1):79-88. 
15. Dobbs MB, Rich MM, Gordon JE, Szymanski DA, Schoenecker PL. Use of an intramedullary rod for treatment of congenital pseudarthrosis of the tibia. A long-term follow-up study. The Journal of bone and joint surgery American volume. 2004;86(6):1186-97.

16. Birke O, Davies N, Latimer M, Little DG, Bellemore M. Experience with the Fassier-Duval telescopic rod: first 24 consecutive cases with a minimum of 1-year follow-up. Journal of pediatric orthopedics. 2011;31(4):458-64.

17. Ligier JN, Metaizeau JP, Prévot J, Lascombes P. Elastic stable intramedullary nailing of femoral shaft fractures in children. The Journal of bone and joint surgery British volume. 1988;70(1):74-7.

18. Popkov A, Foster P, Gubin A, Borzunov D, Popkov D. The use of flexible intramedullary nails in limb lengthening. Expert review of medical devices. 2017;14(9):741-53.

19. Crawford AH, Schorry EK. Neurofibromatosis in children: the role of the orthopaedist. The Journal of the American Academy of Orthopaedic Surgeons. 1999;7(4):217-30.

20. Kitaoka HB, Alexander IJ, Adelaar RS, Nunley JA, Myerson MS, Sanders M. Clinical rating systems for the ankle-hindfoot, midfoot, hallux, and lesser toes. Foot \& ankle international. 1994;15(7):349-53.

21. Cho TJ, Choi IH, Lee KS, Lee SM, Chung CY, Yoo WJ, et al. Proximal tibial lengthening by distraction osteogenesis in congenital pseudarthrosis of the tibia. Journal of pediatric orthopedics. 2007;27(8):915-20.

22. Choi IH, Cho TJ, Moon HJ. llizarov treatment of congenital pseudarthrosis of the tibia: a multitargeted approach using the llizarov technique. Clinics in orthopedic surgery. 2011;3(1):1-8.

23. Aldegheri R. Femoral callotasis. J Pediatr Orthop B. 1997;6(1):42-7.

24. Vigouroux F, Mezzadri G, Parot R, Gazarian A, Pannier S, Chotel F. Vascularised fibula or induced membrane to treat congenital pseudarthrosis of the Tibia: A multicentre study of 18 patients with a mean 9.5-year follow-up. Orthopaedics \& traumatology, surgery \& research : OTSR. 2017;103(5):74753.

25. Kocaoğlu M, Eralp L, Bilen FE, Civan M. Congenital pseudarthrosis of the tibia: Results of circular external fixation treatment with intramedullary rodding and periosteal grafting technique. Acta orthopaedica et traumatologica turcica. 2020.

26. Cho TJ, Choi IH, Lee SM, Chung CY, Yoo WJ, Lee DY, et al. Refracture after llizarov osteosynthesis in atrophic-type congenital pseudarthrosis of the tibia. The Journal of bone and joint surgery British volume. 2008;90(4):488-93.

27. Patterson M. Impact of external fixation on adolescents: an integrative research review. Orthopedic nursing. 2006;25(5):300-8; quiz 9-10.

28. Vanderstappen J, Lammens J, Berger P, Laumen A. Ilizarov bone transport as a treatment of congenital pseudarthrosis of the tibia: a long-term follow-up study. Journal of children's orthopaedics. 2015;9(4):319-24.

29. Johnston CE, 2nd. Congenital pseudarthrosis of the tibia: results of technical variations in the charnley-williams procedure. The Journal of bone and joint surgery American volume. 2002;84(10):1799-810. 
30. Chalopin A, Pesenti S, Peltier E, Bin K, Launay F, Jouve JL. Transplantar intramedullary locking nailing in childhood congenital pseudarthrosis of the tibia: A report of 3 cases. Orthopaedics \& traumatology, surgery \& research : OTSR. 2016;102(4):521-4.

31. Gamble JG, Strudwick WJ, Rinsky LA, Bleck EE. Complications of intramedullary rods in osteogenesis imperfecta: Bailey-Dubow rods versus nonelongating rods. Journal of pediatric orthopedics. 1988;8(6):645-9.

32. Mathieu L, Vialle R, Thevenin-Lemoine C, Mary P, Damsin JP. Association of Ilizarov's technique and intramedullary rodding in the treatment of congenital pseudarthrosis of the tibia. Journal of children's orthopaedics. 2008;2(6):449-55.

33. Pollon T, Sales de Gauzy J, Pham T, Thévenin Lemoine C, Accadbled F. Salvage of congenital pseudarthrosis of the tibia by the induced membrane technique followed by a motorised lengthening nail. Orthop Traumatol Surg Res. 2018;104(1):147-53.

34. Wilkinson JM, Scott BW, Clarke AM, Bell MJ. Surgical stabilisation of the lower limb in osteogenesis imperfecta using the Sheffield Telescopic Intramedullary Rod System. J Bone Joint Surg Br. 1998;80(6):999-1004.

35. Cho TJ, Choi IH, Chung CY, Yoo WJ, Lee KS, Lee DY. Interlocking telescopic rod for patients with osteogenesis imperfecta. J Bone Joint Surg Am. 2007;89(5):1028-35.

36. Anderson DJ, Schoenecker PL, Sheridan JJ, Rich MM. Use of an intramedullary rod for the treatment of congenital pseudarthrosis of the tibia. The Journal of bone and joint surgery American volume. 1992;74(2):161-8.

37. Choi IH, Lee SJ, Moon HJ, Cho TJ, Yoo WJ, Chung CY, et al. "4-in-1 osteosynthesis" for atrophic-type congenital pseudarthrosis of the tibia. Journal of pediatric orthopedics. 2011;31(6):697-704.

38. Zhu GH, Mei HB, He RG, Liu K, Tang J, Wu JY. Effect of distraction osteogenesis in patient with tibial shortening after initial union of Congenital Pseudarthrosis of the Tibia (CPT): a preliminary study. BMC musculoskeletal disorders. 2015;16:216.

\section{Figures}



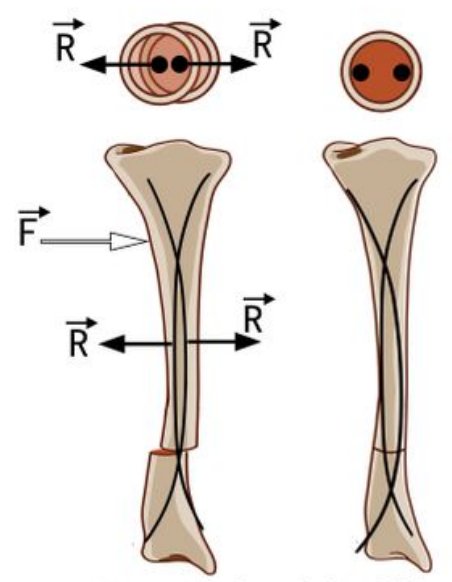

Translational Stability

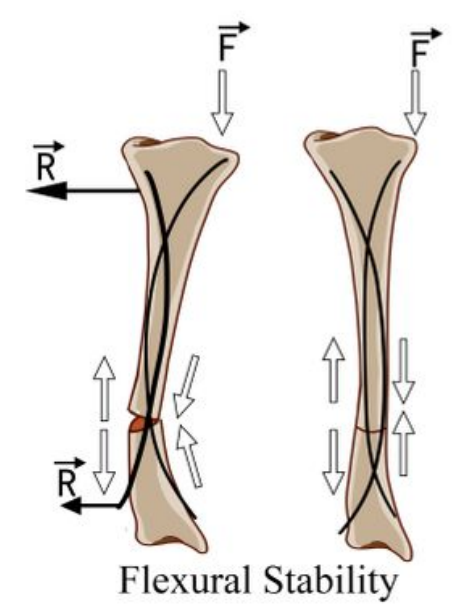

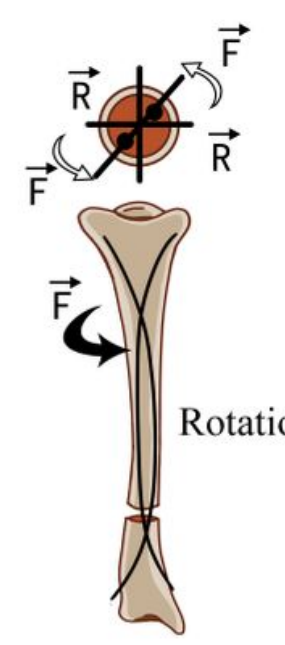

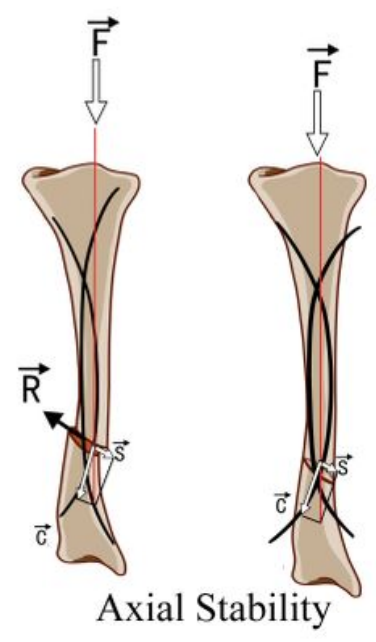

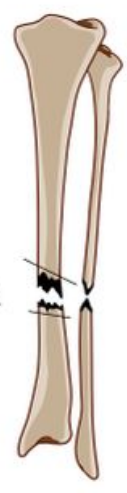

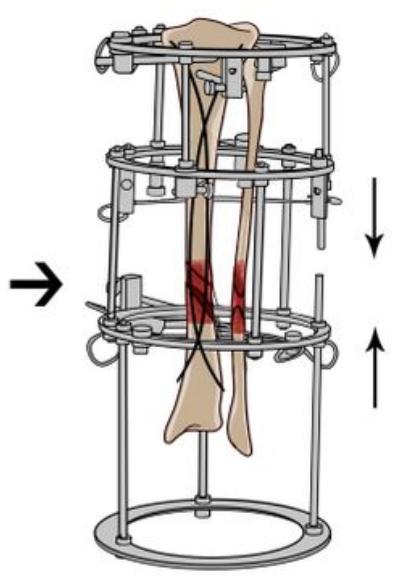

$\mathrm{LLD}>3 \mathrm{~cm}$
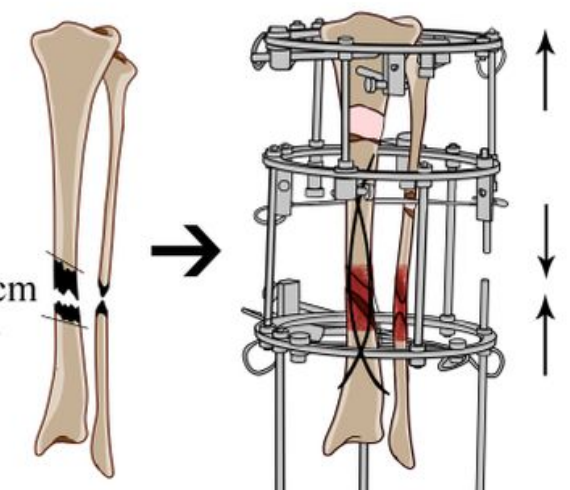

Age $>3 y$

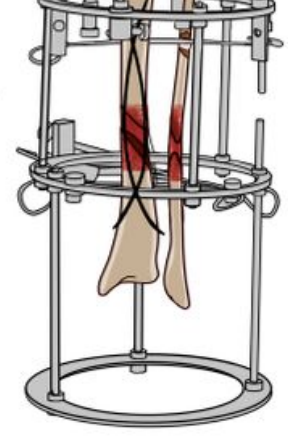

$\mathrm{b}$

\section{Figure 1}

Schematic photographs depicting prebent titanium elastic nailing in CPT treatment. Biomechanical principles of TENs used in CPT. Two prebent TENs were situated in a shape like the Eiffel Tower. The translational, rotational, flexural and axial stability of the nails provide effective support for preventing further refracture and promoting solid union. F: Force acting on the bone; R: Restoring force of the nail; S: Shear force; C: Compressive force (a). Combined therapeutic strategies including acute resection, prebent TENs nailing, bone grafting and dynamic compression with external fixation. The concomitant proximal lengthening (bifocal compression-distraction technique) is applied when more than $3 \mathrm{~cm}$ of residual shortening is anticipated in patients with the age over 3 (b). 

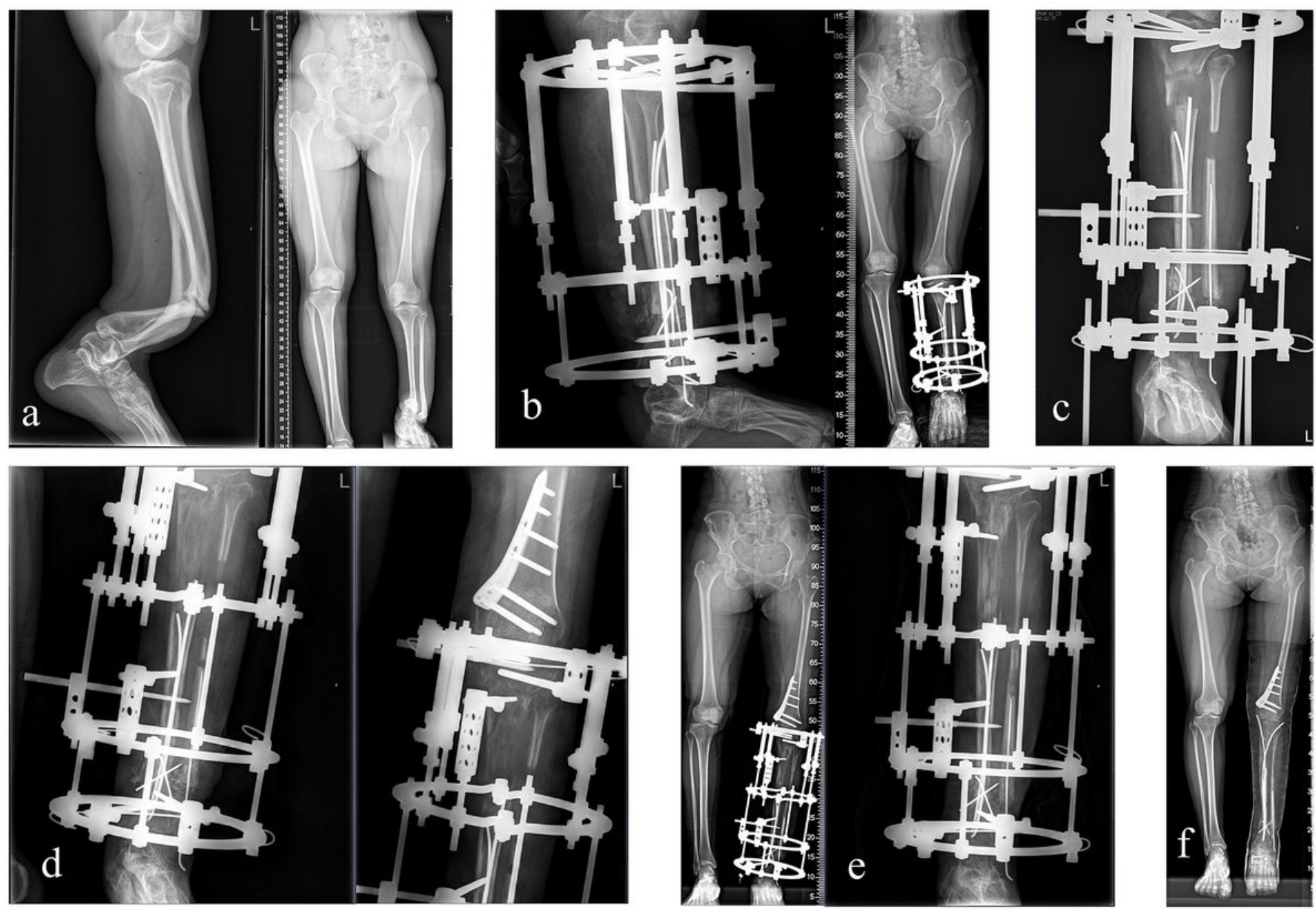

Figure 2

Case 6, a girl with neurofibromatosis who presented with a Crawford type-IV lesion with fibula affected. She received previous surgeries but sustained refracture at 22 years old (a). Pseudarthrosis resection, bone graft, prebent TENs technique and Ilizarov external fixation were performed at 23. The LLD after index surgery was $8.7 \mathrm{~cm}$ (b). 2 months later, the patient underwent bone lengthening at proximal tibia and fibula (c). 6 months after the index surgery, no evidence of union at the pseudarthrosis site. Additional procedures composed of bone grafting and nail changing were performed. Medial distal closewedge osteotomy was also performed for the correction of residual valgus deformity of the knee (d). Secondary union achieved at the pseudarthrosis site 5 months after the additional surgery. Notice the bone generate at the distraction site (e). External fixations were removed 16 months after index surgery. The length gain was $9.5 \mathrm{~cm}$ and the LLD was $7 \mathrm{~mm}$. Tendon lengthening of the Achilles was performed due to the contracture of the Achilles tendon during tibial lengthening. The patients also received calcaneal osteotomy for residual deformity correction (f). 


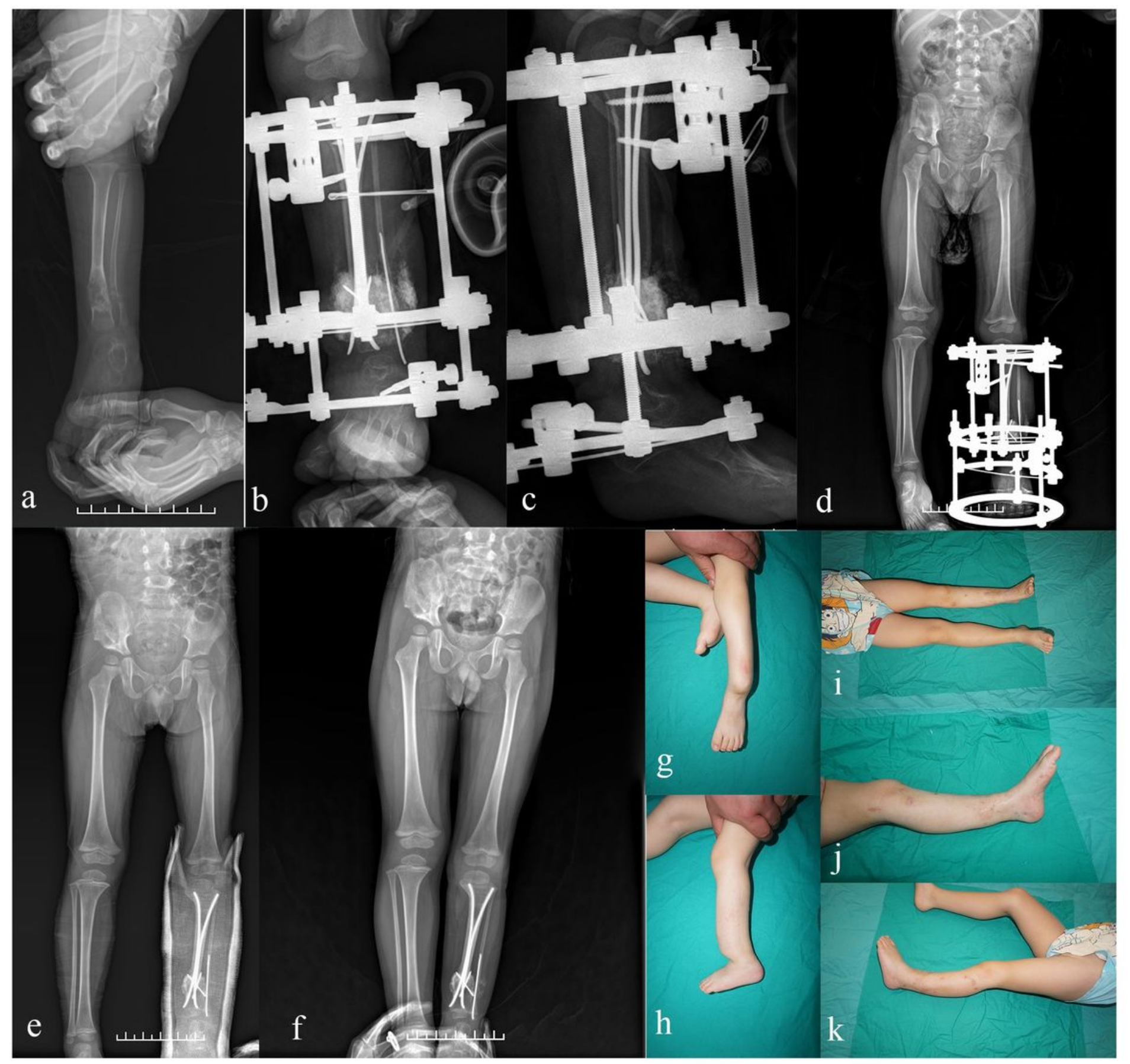

\section{Figure 3}

Case 15: a 2-year-old boy with CPT treated successfully with pseudarthrosis resection, prebent TENs, bone grafting and external fixation. Preoperative anteroposterior X-rays showing Crawford type III CPT with anterolateral bowing of tibia (a). Anteroposterior and lateral radiograph of the same patient taken immediately after combined surgery $(b, c)$. X-ray of 4 months post- operation shows primary union of the pseudarthrosis site (d). Radiograph taken 6 months post-operation shows a well-aligned and remodeled tibia without ankle valgus or tibia angulation (e). The nails were retained in the tibia medullary cavity with 
growth (f). Clinical appearance of the patient before $(g, h)$ and after $(i, j, k)$ the surgery. The patient had an AOFAS score of 82 and a $20 \mathrm{~mm}$ leg-length shortening at the finally follow-up. 